\title{
TINGKAT KELELAHAN (FATIGUE) PADA PENGEMUDI BUS RAPID TRANSIT (BRT) TRANS SEMARANG DAN TRANS JATENG
}

\author{
Edi Purwanto1, Hanif Hidayat ${ }^{2}$, Ethys Pranoto ${ }^{3}$ \\ Politeknik Keselamatan Transportasi Jalan, Tegal, Indonesia., ${ }^{1,2,3}$
}

\begin{abstract}
Abstrak
Penelitian ini bertujuan untuk mengetahui tingkat kelelahan pengemudi BRT Trans Semarang dan Trans Jateng. Jenis penelitian ini adalah penelitian kuantitatif dengan metode penelitian survei. Responden pada penelitian ini adalah pengemudi BRT Trans Semarang dan Trans Jateng. Teknik pengumpulan data yang digunakan adalah: kuisioner IFRC dan observasi. Kuisioner digunakan sebagai sumber data utama, sedangkan observasi digunakan sebagai data pendukung. Teknik analisis data yang digunakan adalah menggunakan statistik deskriptif. Hasil penelitian menunjukkan bahwa tingkat kelelahan pengemudi BRT Trans Semarang dan Trans Jateng adalah: (1) tidak lelah dengan jumlah 0; (2) kelelahan ringan dengan jumlah 84 ; (3) kelelahan sedang dengan jumlah 2; dan (4) kelalahan berat dengan jumlah 0 .
\end{abstract}

Kata Kunci :BRT, pengemudi, tingkat kelelahan

\section{PENDAHULUAN}

Latar Belakang

Meningkatnya mobilitas penduduk di kota besar berakibat pada perlunya peningkatan pelayanan jasa transportasi umum. Transportasi umum dalam kota merupakan kebutuhan bagi sebagian besar masyarakat perkotaan. Sarana yang banyak digunakan oleh masyarakat Indonesia salah satunya yaitu bus. PP No. 55 tahun 2012 menjelaskan Bus adalah Kendaraan Bermotor angkutan orang yang memiliki tempat duduk lebih dari 8 orang, termasuk untuk pengemudi atau yang beratnya lebih dari 3.500 kilogram. Jenis pelayanan bus yang sering dijumpai di kota besar yaitu Bus Rapid Tansit (BRT). BRT adalah sebuah sistem bus yang cepat, nyaman, aman dan tepat waktu apabila ditinjau dari infrastruktur, kendaraan dan jadwal.

Pengoperasian Bus Rapid Transit (BRT) diharapkan dapat menyelesaikan permasalahan transportasi.Trans Semarang dan Trans Jateng merupakan penyelenggara layanan $B R T$ yang bekerjasama dengan beberapa operator bus. Jumlah penumpang $B R T$ semakin meningkat setiap bulannya. Setiap tahunnya pengguna $B R T$ 
mengalami peningkatan dan saat ini diharapkan adanya peningkatan penumpang sebesar $22 \%$ dengan penerapan e-ticket. Hal ini menunjukkan masyarakat mulai sadar untuk menggunakan transportasi umum.

Seorang pengemudi harus mampu bertanggung jawab terhadap keselamatan dirinya, penumpang atau muatan yang dibawa. Pengemudi harus tetap fokus dalam waktu yang cukup lama hingga sampai ke tempat tujuan. Kondisi ini dimungkinkan dapat menyebabkan kelelahan karena mengemudi merupakan aktivitas yang monoton. Pengemudi memiliki tuntutan kerja yang tinggi, khususnya pada penyelenggaraan $B R T$. Hal ini dikarenakan $B R T$ berbeda dengan bus yang beroperasi di jalan lainnya. $B R T$ memiliki trayek tersendiri dengan shelter pemberhentian penumpang khusus dan sejumlah aturan lainnya. Terlebih lagi dengan tugas pokok pengemudi mengantarkan penumpang sampai tujuan dengan selamat dan tepat waktu. Tingginya tuntutan kerja ini dapat menyebabkan terjadinya kelelahan kerja dan mengganggu kesehatan pengemudi.

Laporan KNKT menunjukkan salah satu penyebab terbesar kecelakaan disebabkan karena faktor manusia. Salah satu faktor risiko penyebab kecelakaan karena faktor manusia adalah kelelahan dalam berkendara. Kondisi lelah dapat menimbulkan berkurangnya tingkat kewaspadaan terhadap hal yang terjadi di jalan serta kurang mampu bereaksi dengan cepat dan aman pada saat situasi genting terjadi, sehingga kelelahan dapat menyumbang lebih dari 25\% kecelakaan (KNKT, 2010). Kelelahan adalah suatu mekanisme perlindungan tubuh agar tubuh terhindar dari kerusakan lebih lanjut. Istirahat diperlukan untuk pemulihan tubuh setelah kelelahan (Tarwaka, 2010). Sesuai dengan beberapa penjelasan tersebut penelitian tentang pengoperasian BRT oleh Trans Semarang dan Trans Jateng perlu dilakukan untuk mengetahui tingkat kelelahan pengemudi bus $B R T$.

\section{TINJAUAN PUSTAKA}

\subsection{Durasi danWaktu Kerja}

Durasi merupakan lamanya sesuatu berlangsung, sedangkan waktu kerja adalah waktu yang digunakan untuk melakukan pekerjaan pada satu periode tertentu (Kemenakertrans, 2004). Menurut UU no. 13 tahun 2013 tentang tenaga kerja dijelaskan bahwa waktu kerja adalah 7 (tujuh) jam 1 (satu) hari dan 40 (empat puluh) jam 1 (satu) minggu untuk 6 (enam) harikerja dalam 1 (satu) minggu; atau 8 (delapan) jam 1 (satu) hari dan 40 (empat puluh) jam 1 (satu) minggu untuk 5 (lima)hari kerja dalam 1 (satu) minggu.

Anis dan McConville (1996) berpendapat bahwa saat kebutuhan metabolisme dinamis dan aktivitas melampaui kapasitas energi yang dihasilkan, tenaga kerja akan 
terpengaruh sehingga kelelahan seluruh badan terjadi. Penggunaan energi yang direkomendasikan tidak melebihi $50 \%$ dari tenaga aerobik maksimum untuk kerja 1 jam; $40 \%$ untuk kerja 2 jam dan 33\% untuk kerja 8 jam terus menerus. Nilai tersebut didesain untuk mencegah kelelahan yang dipercaya dapat meningkatkan risiko cedera otot skeletal pada tenaga kerja.

\subsection{Kelelahan}

Lelah adalah suatu mekanisme perlindungan tubuh agar tubuh terhindar dari kerusakan lebih lanjut sehingga terjadi pemulihan setelah istirahat. Istilah kelelahan biasanya menunjukkan kondisi yang berbeda-beda dari setiap individu tetapi semuanya bermuara kepada kehilangan efisiensi dan penurunan kapasitas kerja serta ketahanan tubuh. Hal ini menunjukkan bahwa kelelahan berperan dalam menjaga homeostatis tubuh.

Kelelahan (fatigue) merupakan suatu kondisi yang telah dikenali dalam kehidupan sehari-hari. Istilah kelelahan pada umumnya mengarah pada kondisi melemahnya tenaga untuk melakukan suatu kegiatan, walaupun ini bukan merupakan satu-satunya gejala.Secara harfiah fatigue dapat diartikan secara sederhana sama dengan kelelahan yang sangat (deep tiredness), mirip stres, bersifat kumulatif. fatigue sering dihubungkan dengan kondisi kurang tidur, kondisi akibat tidur yang terganggu, atau kebutuhan kuat untuk tidur yang berhubungan dengan panjangnya waktu kerja dan stres-stres kerjayang bervariasi.

Fatigue sering dikaitkan dengan perasaan lelah yang bersifat subjektif, hilangnya perhatian bersifat temporer, dan menurunnya respon psikomotor. Selain itu fatigue juga berhubungan dengan gejala-gejala yang dikaitkan dengan menurunnya efisiensi performadan ketrampilan. Fatigue juga kerap dikaitkan dengan kondisi nonpatologis yang dapat membuat kemampuan seseorang menurun dalam mempertahankan kinerja yang berhubungan dengan stres fisik maupun mental,atau terganggunya siklus biologis tubuh (jet lag).

Kelelahan kerja merupakan suatu mekanisme perlindungan agar terhindar dari kerusakan lebih lanjut, sehingga dengan demikian terjadilah pemulihan setelah istirahat (Tarwaka, 2004).Kelelahan adalah perpaduan dari wujud penurunan fungsi mental dan fisik yang menghasilkanberkurangnya semangat kerja sehingga mengakibatkan efektifitas dan efisiensi kerja menurun (Saito, 1999). Teori lain diungkapkan oleh Kroemer (1997) yang menjelaskan bahwa kelelahan kerja merupakan gejala yang ditandai dengan adanya perasaan lelah. Selain itu adanya rasa segan serta aktivitas yang akan melemah serta ketidakseimbangan pada kondisi tubuh. Kelelahan juga dapatmempengaruhi kapasitas fisik, mental dan tingkat emosional seseorang. Hal ini 
dapat mengakibatkan kurangnya kewaspadaan yang ditandai dengan kemunduran reaksi pada sesuatu degan berkurangnya kemampuan motorik (Australia Safety Compensation Council, 2006).

\subsection{FaktorPenyebabKelelahan}

Faktor penyebab kelelahan kerja menurut Siswanto (1991) dijelaskan sebagai berikut

a. Pengorganisasian kerja yang tidak menjamin istirahat dan rekreasi, variasi kerja dan intensitas pembebanan fisik yang tidak serasi dengan pekerjaan.

b. Faktor Psikologis misalnya rasa tanggungjawab dan khawatir yang berlebihan serta konflik yang kronis atau menahun.

c. Lingkungan kerja yang tidak menjamin kenyamanan kerja serta tidak menimbulkan pengaruh negatif terhadap kesehatan pekerja.

d. Status kesehatan dan status gizi.

e. Monoton yaitu pekerjaan atau lingkungan kerja yang membosankan.

\subsection{GejalaKelelahan}

Secara umum gejala kelelahan dapat dimulai dari yang sangat ringan sampai perasaan yang sangat melelahkan. Gejala kelelahan (fatigue symptoms) secara subyektif dan obyektif menurut Budiono (2003) adalah :

a. Perasaan lesu, ngantuk dan pusing.

b. Kurang mampu berkonsentrasi.

c. Berkurangnya tingkat kewaspadaan.

d. Persepsi yang buruk dan lambat.

e. Berkurangnya gairah untuk bekerja.

f. Menurunnya kinerja jasmani dan rohani.

\subsection{Pengukuran Kelelahan}

Pengukuran kelelahan menggunakan Subjective Self Rating Test dari Industrial Fatigue Research Committee (IFRC) Jepang. IFRC merupakan salah satu kuesioner yang dapat mengukur tingkat kelelahan subjektif. Kuesioner tersebut berisi 30 daftar pertanyaan yang terdiri dari:

a. 10 pertanyaan tentang pelemahan kegiatan.

b. 10 pertanyaan tentang pelemahan motivasi.

c. 10 pertanyaan tentang gambaran kelelahan fisik.

Jawaban untuk kuesioner IFRC terbagi menjadi kategori besar yaitu Sangat Sering (SS) dengan nilai 4, Sering (S) dengan nilai 3, Kadang-Kadang (K) dengan nilai 2 dan 
Tidak Pernah (TP) dengan nilai 1. Dalam menentukan tingkat kelelahan, jawaban tiap pertanyaan dijumlahkan lalu disesuaikan dengan kategori tertentu. Kategori yang diberikan adalah:
a. Nilai $30=$ Tidak Lelah
b. Nilai 31-60 = Kelelahan Ringan
c. Nilai 61-90 = Kelelahan Menengah
d. Nilai $91-120=$ KelelahanBerat

\subsection{Kerangka Pikir}

Kondisi ketika kebutuhan metabolisme dinamis dan aktivitas melampaui kapasitas energi yang dihasilkan, pengemudi akan terpengaruh sehingga kelelahan seluruh badan akan terjadi. Penggunaan energi yang direkomendasikan sebaiknya tidak melebihi $50 \%$ dari tenaga aerobik maksimum untuk kerja 1 jam; 40\% untuk kerja 2 jam dan 33\% untuk kerja 8 jam terus menerus. Nilai tersebut didesain untuk mencegah kelelahan yang dipercaya dapat meningkatkan risiko cedera otot skeletal pada tenaga kerja.

Kelelahan (fatigue) merupakan suatu kondisi yang telah dikenali dalam kehidupan sehari-hari. Istilah kelelahan pada umumnya mengarah pada kondisi melemahnya tenaga untuk melakukan suatu kegiatan, walaupun ini bukan merupakan satu-satunya gejala. Fatigue sering dikaitkan dengan perasaan lelah yang bersifat subjektif, hilangnya perhatian bersifat temporer, dan menurunnya respon psikomotor. Selain itu fatigue juga berhubungan dengan gejala-gejala yang dikaitkan dengan menurunnya efisiensi performadan ketrampilan. Secara umum gejala kelelahan dapat dimulai dari yang sangat ringan sampai perasaan yang sangat melelahkan. Gejala kelelahan (fatigue symptoms) secara subyektif dan obyektif.

Pengukuran kelelahan dapat dilakukan menggunakan Subjective Self Rating Test dari Industrial Fatigue Research Committee (IFRC) Jepang. IFRCmerupakan salah satu kuesioner yang dapat mengukur tingkat kelelahan subjektif. 


\section{METODE PENELITIAN}

\subsection{Bagan Alir Penelitian}

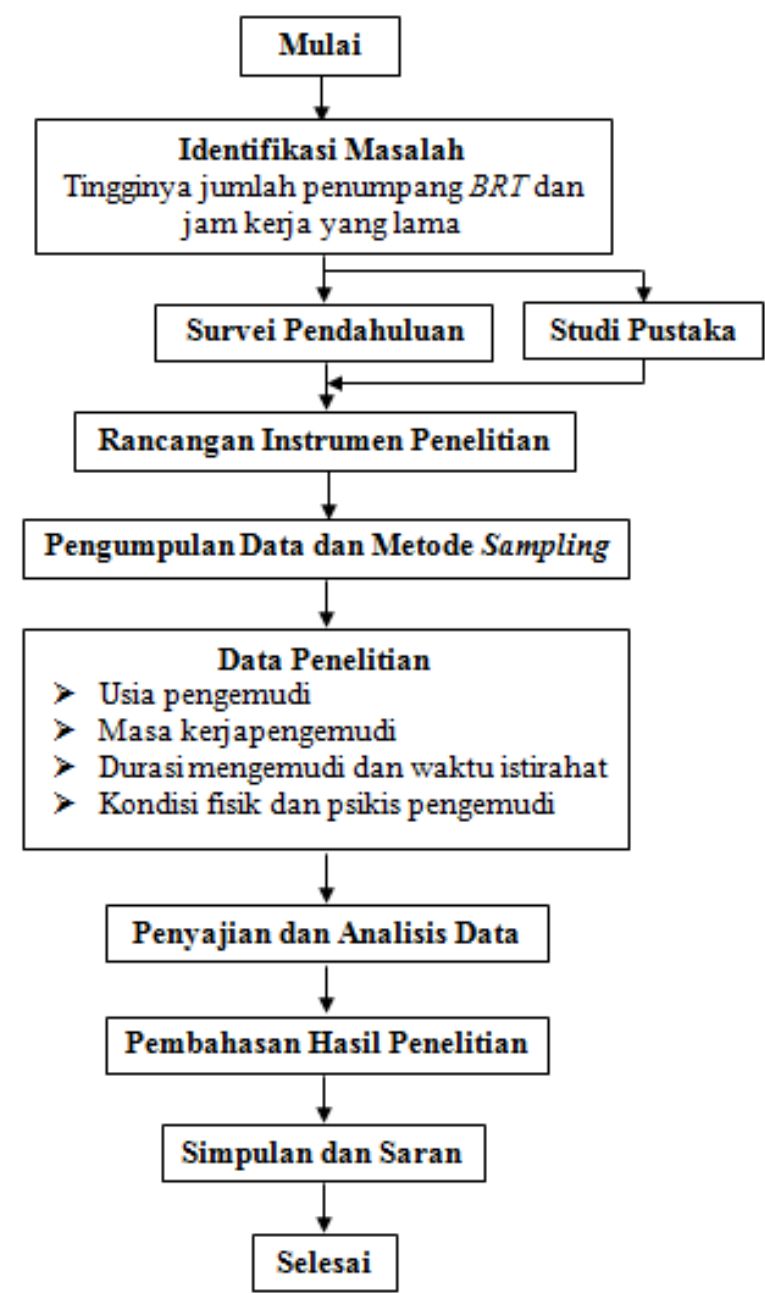

Gambar 1. Bagan AlirPenelitian

\subsection{Tempat dan Waktu Penelitian}

a. Lokasi penelitian : Pool BRT Trans Semarang dan Trans Jateng

b. Waktu penelitian : November 2017 - Desember 2017

\subsection{Populasi dan Sampel Penelitian}

Populasi pada penelitian ini adalah BRT Trans Semarang dan Trans Jateng. Objek pada penelitian ini adalah tingkat kelelahan pengemudi, sedangkan subjek pada penelitian ini adalah pengemudi $B R T$, dimana pengemudi $B R T$ dijadikan sebagai respoden penelitian. Daftar nama pool BRT Trans Semarang dan Trans Jateng di Kota Semarang dan Kabupaten Semarang yang menjadi populasi dan jumlah pengemudi bus $B R T$ yang digunakan sebagai responden pada penelitian ini adalah sebagai berikut: 
Tabel 1. Daftarpool BRTTrans Semarang dan Trans Jatengdanjumlahpengemudi bus $B R T$.

\begin{tabular}{ccc} 
No & Koridor BRT & JumlahPengemudiBRT \\
\hline 1 & Koridor 1 & 10 \\
\hline 2 & Koridor 2 & 10 \\
\hline 3 & Koridor 3 & 16 \\
\hline 4 & Koridor 4 & 24 \\
\hline 5 & Koridor 5 & 7 \\
\hline 6 & Koridor 1 & 18 \\
\hline
\end{tabular}

Teknik pengambilan sampel pada penelitian ini menggunakan teknik random sampling yaitu teknik penentuan sampel secara acak terhadap semua anggota populasi. Ukuran pengambilan sampel dihitung dengan rumus Krejcie dan Morgan yaitu:

$$
S=\frac{\lambda^{2} \cdot N \cdot P \cdot Q}{d^{2}(N-1)+\lambda^{2} \cdot P \cdot Q}
$$

dimana $S$ = banyak nya sampel, $N=$ jumlah anggota populasi, $P$ dan $Q=0,5$ sebagai konstanta untuk menghasilkan ukuran sampel maksimum, $d=0,05$ yaitu tingkat kesalahan yang diperbolehkan, dan $\lambda^{2}=3,841$ yaitu nilai dari tabel. Berdasarkan rumus tersebut, populasi dengan jumlah 141 responden maka besarnya sampel yang diperlukan adalah 86 responden.

\subsection{MetodePenelitian}

Metode penelitian yang digunakan adalah statistik deskriptif dimana hasil survei yang dideskripsikan berupa tingkat kelelahan pengemudi pada BRT Trans Semarang dan Trans Jateng. Penelitian ini dimaksudkan untuk memotret tingkat kelelahan pengemudi BRT Trans Semarang dan Trans Jateng, sehingga menggunakan jenis penelitian kuantitatif dengan metode penelitian survei. Pada penelitian survey ini, informasi diperoleh dari pengemudi $B R T$ sebagai sumber utama dengan menggunakan kuisioner serta didukung wawancara dan observasi sebagai pendukung data kuisioner. Penelitian survey ini menggunakan pendekatan deskriptif kuantitatif untuk mengukur tingkat kelelahan pengemudi BRT Trans Semarang dan Trans Jateng. Penelitian ini dilakukan untuk menghimpun fakta yang ada di lapangan, tetapi tidak melakukan pengujian hipotesa. 


\subsection{Teknik Pengumpulan Data}

Kuisione digunakan untuk memperoleh data secara obyektif yakni berupa daftar pernyataan yang harus dijawab oleh responden. Kuisioner ditujukan kepada seluruh pengemudi BRT Trans Semarang dan Trans Jateng. Materi kuisioner berupa pernyataan tentang pengelolaan yang terdiri dari: pelemahan kegiatan, pelemahan motivasi dan gambaran kelelahan fisik.

\subsection{InstrumenPenelitian}

Kuisioner IFRC digunakan untuk memperoleh data secara obyektif yakni berupa daftar pernyataan yang harus dijawab oleh responden. Kuisioner ditujukan kepada pengemudi BRT Trans Semarang dan Trans Jateng. Materi kuisioner berupa pernyataan tentang pengelolaan yang terdiri dari: pelemahan kegiatan, pelemahan motivasi dan gambaran kelelahan fisik.

\subsection{Teknik Analisa Data}

Hasil kuisioner tingkat kelelahan pengemudi BRT Trans Semarang dan Trans Jateng dianalisis menggunakan statistic deskriptif. Analisis data secara statistik deskriptif merupakan penyederhanaan data menjadi bentuk yang mudah dibaca dan dipahami. Statistik deskriptif yang digunakan untuk menggambarkan kondisi variabel yang diteliti yakni tingkat kelelahan pengemudi BRT Trans Semarang dan Trans Jateng yang meliputi: pelemahan kegiatan, pelemahan motivasi dan gambaran kelelahan fisik menggunakan tabel yang menampilkan jumlah skor pada setiap indikator.

Hasil jumlah skor kuisioner ditafsirkan untuk mengetahui kualitas indikator yang diukur. Penafsiran skor kuisioner pada penelitian ini berdasarkan daftar distribusi skor berikut:

Tabel 2. Distribusi tingkat kelelahan pengemudi

\begin{tabular}{cc}
\hline Kategori & Skor \\
\hline Tidak Lelah & 30 \\
\hline Kelelahan Ringan & $31-60$ \\
\hline Kelelahan Sedang & $61-90$ \\
\hline Kelelahan Berat & $91-120$ \\
\hline
\end{tabular}




\subsection{Jadwal Penelitian}

a. Tahap Pra-Survei dilakukan dengan meninjau lokasi penelitian dan perijinan terhadap instransi serta perusahaan terkait pelaksanaan penelitian yang akan dilakukan.

b. Tahap Survei berupa pengumpulan data dengan cara observasi dan pengisian kuesioner kelelahan IFRC yang dilakukan oleh pengemudi setelah pengemudi melakukan aktivitasnya.

c. Pasca Survei dilakukan setelah pelaksanaan survey selesai dilaksanakan.

\section{HASIL DAN PEMBAHASAN}

\subsection{Deskripsi Data Hasil Penelitian}

Penelitian ini merupakan penelitian statistik deskriptif dengan menghitung data dari penelitian yang telah dilakukan. Hasil penelitian yang berupa data kuesioner merupakan indikator utama pengukuran tingkat kelelahan pada pengemudi BRT. Analisis data dilakukan untuk mengetahui tingkat kelelahan pengemudi yang dilakukan secara deskriptif. Tingkat kelelahan pengemudi dapat diketahui dengan penghitungan data sesuai dengan skala yang telah ditentukan untuk pengambilan langkah selanjutnya terhadap pelaksanaan $B R T$.

Peneliti melakukan survei terhadap pengemudi $B R T$ pada semua koridor yang ada yaitu koridor 1 sampai dengan 6 BRT Trans Semarang dan koridor 1 di BRT Trans Jateng. Data yang diambil berupa pola kerja dan tingkat kelelahan melalui kuesioner yang telah dibuat sesuai dengan kondisi yang ada.

Sebelum melakukan pengambilan data, peneliti melakukan pra-survei untuk mengetahui kondisi perusahaan dan instansi tempat pelaksanaan penelitian. Tahapan ini diilakukan sekaligus dengan perijinan terhadap badan terkait agar penelitian bisa berjalan dengan lancar tanpa adanya kendala apapun.

Pengambilan data pada tahapan survei, peneliti meminta pengemudi untuk mengisi kuisioner yang telah dibuat.Tujuan agar dapat mengetahui kondisi pengemudi setelah jam kerja pada satu hari tersebut. Setelah didapat hasil maka dilakukan pengolahan data yang bertujuan mengetahu tingkat kelelahan pengemudi $B R T$ tersebut.

\subsection{Analisis Data Hasil Penelitian}

\section{a. Usia Pengemudi BRT Trans Semarang dan Trans Jateng}

Perolehan dara dari hasil kuesioner diketahui beberapa data karakteristik responden. Karakteristik responden dalam penelitian ini dimulai dari usia 25 Tahun hingga usia paling tua yaitu 65 Tahun. Untuk keperluan penelitian, usia digolongkan menjadi 3 kategori yaitu kategori kurang dari 30 tahun ( $<30$ tahun), 31-45 tahun dan 
lebih dari 45 tahun (> 45 tahun). Adapaun pengklasifikasian berdasarkan kategori tersebut, yaitu:

Tabel 3.Karakteristik responden berdasarkan usiaTrans Semarang dan Trans Jateng

\begin{tabular}{cccc} 
Variable & Katagori & Jumlah & $\%$ \\
\hline \multirow{3}{*}{ Usia } & $<30$ & 5 & $5,81 \%$ \\
\cline { 2 - 4 } & $31-45$ & 25 & $29,07 \%$ \\
\cline { 2 - 4 } & $>45$ & 56 & $65,12 \%$ \\
\cline { 2 - 4 } & Total & 86 & \\
\hline
\end{tabular}

\section{b. Masa Kerja Pengemudi BRTTrans Semarang dan Trans Jateng}

Masa kerja pengemudi juga merupakan hal perlu diketahui. Berikut merupakan karakteristik responden berdasarkan massa kerja. Dimana massa kerja yang dimaksud adalah masa kerja selama menjadi pengemudi bus.

Tabel 4. Masa kerja pengemudi Bus BRTTrans Semarang dan Trans Jateng

\begin{tabular}{cccc} 
Variable & Katagori & Jumlah & $\%$ \\
& $<1$ Tahun & 0 & 0 \\
\cline { 2 - 4 } Masa Kerja & $5-10$ Tahun & 5 & $5,81 \%$ \\
\cline { 2 - 4 } & $>10$ tahun & 81 & $94,19 \%$ \\
\cline { 2 - 4 } & Total & 86 & \\
\cline { 2 - 4 } & &
\end{tabular}

\section{c. Tingkat Kelelahan Pengemudi BRT Trans Semarang dan Trans Jateng}

Berdasarkan pengukuran tingkat kelelahan secara subjektif dengan menggunakan kuesioner IFRC pada pengemudi bus BRT Trans Semarang dan Trans Jateng, didapatkan hasil rata-rata skor yaitu sebesar 34,38. Dimana skor tersebut kemudian disesuaikan dengan kategori tingkat kelelahan. Berikut merupakan distribusi tingkat kelelahan pengemudi berdasarkan kuesioner Industrial Fatigue Research Committee (IFRC).

Tabel 5. Distribusi tingkat kelelahan pengemudi

\begin{tabular}{cccc}
\hline Kategori & Skor & Jumlah & $\%$ \\
\hline Tidak Lelah & 30 & 0 & 0 \\
\hline Kelelahan Ringan & $31-60$ & 84 & $97,68 \%$ \\
\hline Kelelahan Sedang & $61-90$ & 2 & $2,32 \%$ \\
\hline Kelelahan Berat & $91-120$ & 0 & 0
\end{tabular}

Rata-rata kelelahan yang dialami oleh 86 pengemudi ini adalah kelelahan dengan kategori tingkat ringan dan belum mencapai tingkat kelelahan kerja yang 
membahayakan yaitu kelelahan berat yang dapat berpotensi tinggi menyebabkan kelelahan dan gangguan kesehatan. Hal ini dikarenakan oleh waktu istirahat yang cukup dan penggunaan waktu istirahat yang baik yang dilakukan oleh pengemudi. Meskipun dalam pengaturan waktu istirahat yang dilakukan oleh pengemudi ini sudah sesuai dengan Undang-Undang No. 22 Tahun 2009 yang menyebutkan bahwa setelah mengemudikan kendaraan bermotor selam 4 (empat) jam berturutturut wajib beristirahat paling singkat setengah jam, namun apabila waktu kerja dan istirahat resmi telah diatur dengan tepat (kapasitas kerja = beban utama + beban tambahan) maka dengan sendirinya istirahat curian dan istirahat spontan dapat diminimalisasikan. Karena semakin lelah kondisi seorang pekerja maka akan semakin banyak dilakukan istirahat curian oleh pekerja. (Tarwaka, 2004).

Hasil tingkat kelelahan pengemudi bus BRT Trans Semarang dan Trans Jateng berdasarkan kuesioner IFRC jika dilihat dari gejala kelelahan yang dialami oleh pengemudi yaitu lelah pada mata, mengantuk, dan sakit kepala yang tidak jelas penyebabnya, pucat pada wajah, menguap, serta haus. Gejala kelelahan tersebut hanya saat-saat tertentu atau kadang-kadang dirasakan oleh pengemudi. Oleh karena itu dari analisa diatas, diketahui bahwa kelelahan yang dialami oleh pengemudi BRT Trans Semarang dan Trans Jateng adalah kelelahan dengan tingkat ringan.

\section{PENUTUP}

\subsection{Kesimpulan}

Tingkat kelelahan pengemudi sesuai dengan hasil pengolahan data maka dapat disimpulkan bahwa kelelahan yang dialami oleh pengemudi bus BRT Trans Semarang dan Trans Jateng dikategorikan pada kelelahan tingkat ringan. Gejala kelelahan yang dialami oleh pengemudi yaitu lelah pada mata, mengantuk dan sakit kepala yang tidak jelas penyebabnya sedangkan ciri kelelahan yang tampak pada saat mengemudi diantaranya pucat pada wajah, menguap, serta haus. 


\subsection{Saran}

Berdasarkan data penelitian dapat diketahui bahwa kelelahan yang dialami pengemudi adalah kelelahan ringan. Kelelahan ringan yang dibiarkan dapat berbahaya bagi kesehatan dan keselamatan saat mengemudi. Hal yang harus dilakukan oleh pengemudi dan pihak operasional adalah saling berkoordinasi secara lebih mendalam agar didapatkan solusi tentang jam istirahat yang cukup bagi pengemudi.

\section{DAFTAR PUSTAKA}

A. M. Sugeng Budiono. (2003). Bunga rampai hiperkes dan kesehatankerja. Semarang: Badan Penerbit UNDIP.

Anis, J.F. and McConville, J.T. (1996). Anthropometry "Occupational ergonomics theory and aplication". New York: Marcel Dekker Inc.

Australian Safety and Compensation Council. (2006). Summary of recent indicative research: Work-Related Fatigue. Australian Government: Australia.

KNKT. (2016). Database Data InvestigasiKecelakaan LLAJ Tahun 2010-2016. Jakarta: Media Release KNKT.

Kroemer, K.H.E. (1999). Assessment of human muscle strength regulation. Proceeding in Annual Conference of Human Factor Society. Human Factor Society Santa Monica, California. 1999, 19-20.

Menakertrans. (2003). Keputusan Menteri Tenaga danTransmigrasiRepublik Indonesia Nomor :Kep. 234 /Men/2003, Tahun 2003, tentangWaktuKerjadan/stirahatpadaSektor Usaha Energi Dan SumberDaya Mineral Pada Daerah Tertentu.

Presiden. (2012). Peraturan Pemerintah Nomor 55, Tahun 2012, tentang Kendaraan.

Republik Indonesia. (2013). Undang-Undang RI Nomor 13 Tahun 2013, tentang Tenaga Kerja.

Saito. (1999). Measurement of fatigue in industries [Versielektronik]. International Journal of Fatigue. 1999:37,134-142.

Siswanto, A. (1991). Kebisingan. Surabaya: BalaiHiperkesdanKeselamatanKerja.

Tarwaka. (2010). Ergonomi industri. Surakarta: Harapan Press. 